\title{
The status of technologies to measure forest biomass and structural properties: state of the art in SAR tomography of tropical forests
}

\begin{abstract}
(150 to 200 words):
Synthetic Aperture Radar (SAR) Tomography (TomoSAR) is an emerging technology to image the 3D structure of the illuminated media. TomoSAR exploits the key feature of microwaves to penetrate into vegetation, snow, and ice, hence providing the possibility to see features that are hidden to optical and hyper-spectral systems. The research on the use of PBand waves, in particular, has been largely propelled since 2007 in experimental studies supporting the future spaceborne Mission BIOMASS, to be launched in 2022 with the aim of mapping forest Above Ground Biomass (AGB) accurately and globally. The results obtained in the frame of these studies demonstrated that TomoSAR can be used for accurate retrieval of geophysical variables such as forest height and terrain topography, and, especially in the case of dense tropical forests, to provide a more direct link to AGB. This paper aims at providing the reader with a comprehensive understanding of TomoSAR and its application for remote sensing of forested areas, with special attention to the case of tropical forests. We will introduce the basic physical principles behind TomoSAR, present the most relevant experimental results of the last decade, and discuss the potentials of BIOMASS tomography.
\end{abstract}

\begin{abstract}
Authors: Montpellier, France Milan, Italy

Thuy Le Toan, Centre d'Etudes Spatiales de la BIOsphère (CESBIO), Toulouse, France

Ludovic Villard, Centre d'Etudes Spatiales de la BIOsphère (CESBIO), Toulouse, France

Jerome Chave, Centre national de la recherche scientifique (CNRS), Toulouse, France
\end{abstract}

Stefano Tebaldini, Politecnico di Milano, Dipartimento di Elettronica, Informazione e Bioingegneria (DEIB), Milan, Italy

Dinh Ho Tong Minh, National Research Institute of Science and Technology for Environment and Agriculture (IRSTEA),

Mauro Mariotti d'Alessandro, Politecnico di Milano, Dipartimento di Elettronica, Informazione e Bioingegneria (DEIB),

\section{Keywords:}

Remote Sensing; Forestry; Synthetic Aperture Radar (SAR); Tomography; Microwaves; Above Ground Biomass; Forest height; Terrain topography; BIOMASS.

\section{Corresponding author:}

Stefano Tebaldini

Dipartimento di Elettronica, Informazione e Bioingegneria

Politecnico di Milano

Via Ponzio 34/5, 20133, Milan, Italy

Email: stefano.tebaldini@polimi.it

Phone: +390223993614

Fax: +390223993443 


\section{Introduction}

Synthetic Aperture Radar (SAR) imagery is nowadays a most relevant technology for remote sensing of the natural environment, as witnessed by the increasing number of spaceborne SARs and their improving performance (Moreira, 2014). Indeed, SAR systems provide a powerful and unique combination of features relevant to remote sensing, such as large spatial coverage, resolution of the order of few meters, and the possibility to operate largely independently of weather conditions and solar illumination (Curlander and McDonough, 1991). Another most relevant feature, which is peculiar to microwave systems, is the capability to probe the interior part of the illuminated media. Indeed, microwaves, specially at long wavelength, can penetrate for meters, or even tens of meters, into natural media that are non-transparent at optical frequencies, as it is the case for vegetation, snow, ice, and sand. This feature makes SAR data sensitive to the vertical structure of those media, hence providing access to features that are hidden to optical and hyper-spectral sensors, see for examples (Mariotti d'Alessandro et al., 2013), (Tebaldini et al., 2016), (Rekioua et al., 2017), (Paillou et al., 2003). The downside is that microwave scattering from distributed media may be quite complex, involving a number of different mechanisms through which the wave is backscattered. Considering forested areas, which are the focus of this paper, the Radar signal is determined by direct scattering from elements within the vegetation canopy, from the underlying terrain, as well as from multiple scattering resulting from the waves bouncing off the ground in the direction of the Radar after being scattered downwards by the tree canopy and trunks (Treuhaft and Siqueira, 2000), (Mariotti d'Alessandro et al., 2013), (Papathanassiou and Cloude, 2001), (Smith-Jonforsen et al., 2007), (Lin and Sarabandi,1992). As a result, SAR data analysis has traditionally been carried out based on mathematical models that provide the best trade-off between the variety of phenomena captured by the model and the possibility to produce robust estimates of forest parameters through model inversion, see for example (Freeman, 2007), (Treuhaft and Siqueira, 2000).

The introduction of SAR Tomography (TomoSAR) techniques has opened up the way to a completely new approach to look at SAR data. A TomoSAR survey is typically obtained by repeatedly flying a Radar to acquire multiple SAR images of the same area from different trajectories, as shown in the left panel of figure 1 . These data are then focused via digital signal processing algorithms to produce a collection of voxels that represent the backscattered energy in three dimensions, thus providing the possibility to see how the vertical structure of the vegetation interacts with the wave (Reigber and Moreira, 2000), (Mariotti d'Alessandro and Tebaldini, 2012). An example is shown in the right panel of figure 1, where a 3D representation of a tropical forest at the Paracou Ecological Research Station, French Guiana, is provided by displaying four horizontal tomographic sections.
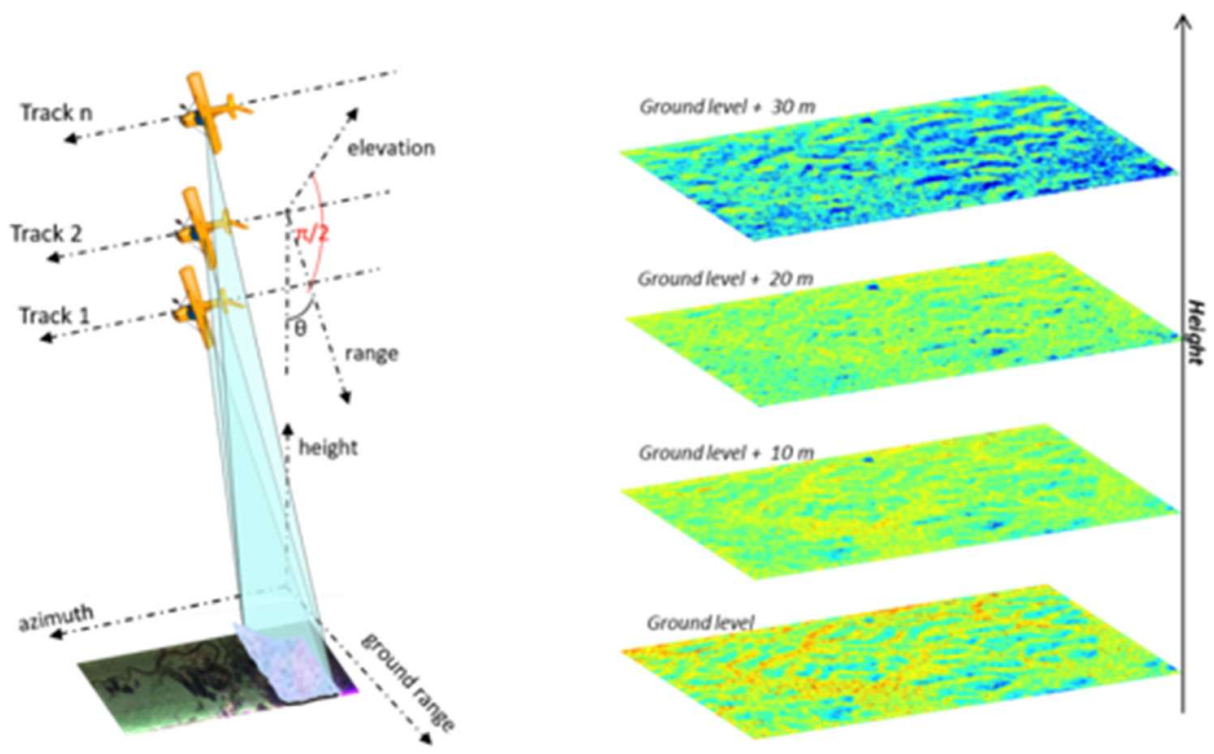

Figure 1. Left: TomoSAR illumination. Right: Tomographic sections. Data: TropiSAR, P-Band, Paracou Research Station. Data acquisition by ONERA. 
The use of TomoSAR for investigating forest structure has been under analysis for more than a decade, based on theoretical studies and on the analysis of real data from airborne campaigns. Research on the use of P-Band waves (wavelength $\approx 70$ $\mathrm{cm}$ ), in particular, has accelerated since 2007 in view of the future P-Band spaceborne Mission BIOMASS, which will be launched by the European Space Agency (ESA) in 2022 with the aim of providing AGB accurately and globally (ESA, 2012). Early research was generally aimed at retrieving information about the vertical structure of the vegetation, to complement traditional radiometric and interferometric measurements, (Tebaldini, 2010), (Mariotti d'Alessandro and Tebaldini, 2012), (Frey and Meyer, 2011a), (Frey and Meyer, 2011b). Boosted by first encouraging results, successive studies demonstrated that P-Band TomoSAR could effectively be used to derive an accurate characterization of forest structural properties and of the interaction with Radar waves. The works in (Frey and Meyer, 2011a), (Tebaldini and Rocca, 2012), and (Mariotti d'Alessandro et al, 2013), for example, first showed the variation of wave polarization inside the vegetation layer, which could then be used as a fingerprint to detect and quantify the arising of double bounce scattering from ground-trunk interactions, see in particular (Mariotti d'Alessandro et al, 2013). TomoSAR was also demonstrated to be a most valuable tool to retrieve forest canopy height (Tebaldini and Rocca, 2012), (Ho Tong Minh et al., 2016), and, by virtue of the penetration capabilities of P-Band waves, sub-canopy terrain topography (Tebaldini, 2010), (Gatti et al., 2011), (Mariotti d'Alessandro and Tebaldini, 2018). A most important result concerning the application of P-Band TomoSAR in tropical forests is the one published in (Ho Tong Minh et al., 2014a). In that paper, it was first shown by analyzing a tropical site in French Guiana that tomographic intensity at the height of the 'main canopy' in a tropical forest provides a much higher correlation to forest AGB than traditional 2D SAR intensity. It was later shown that model parameterization at one site could be used to predict AGB based on TomoSAR at two sites in French Guiana in (Ho Tong Minh et al., 2016), and below we extend this to three more forest sites in Gabon.

Along with P-Band, research on Tomography was carried out at L-Band (wavelength $\approx 25 \mathrm{~cm}$ ) as well, motivated by the proposal of the L-Band bistatic SAR systems Tandem-L and SAOCOM-CS (Moreira et al., 2015), (ESA, 2015). Most noticeable results are those concerning separation of ground and volume scattering gr (Pardini and Papathanassiou, 2017), (Tebaldini and Rocca, 2012), the impact of weather changes (Pardini et al., 2014), and a study on AGB retrieval from vertical structure parameters extracted using TomoSAR (Toraño Caicoya et al., 2015). Most recently, a study showed that L-Band TomoSAR provides greatly improved correlation to forest AGB in boreal forests (Blomberg et al., 2018). It is worth noting that most research at L-Band has thus far been focused on temperate and boreal forests, under the general assumption that L-Band waves can hardly penetrate to the ground in dense tropical forests. Yet, in two recent studies carried out in Gabon it was clearly observed that L-Band TomoSAR can actually characterize the full vertical structure of tropical forests (La Valle et al. 2017), (Pardini et al., 2018).

The aim of this paper is to provide the reader with a comprehensive understanding of TomoSAR and its application for remote sensing of forested areas, by introducing the basic physical principles behind TomoSAR, the most relevant experimental results obtained in the last decade, and the potential for spaceborne applications. In the exposition, we will mostly focus on the case of P-Band TomoSAR and tropical forests. This choice is due to two reasons. In the first place, it is in tropical environments that the use of Tomography appears today to make the most significant difference with respect to conventional SAR and interferometric SAR (InSAR) methods. The second reason is the upcoming BIOMASS Mission, which will implement tomographic imaging for the first 14 months of its lifetime, with optimized performance on equatorial areas (ESA, 2012).

This paper is structured as follows. The basic principles required to understand tomographic imaging are introduced and discussed in section 2. Section 3 is intended to provide a brief introduction to forest scattering from forested areas. The use of TomoSAR of the remote sensing of forested areas is discussed in sections 4, 5, and 6, which focus on imaging of the forest structure, forest biomass, and the retrieval of forest height and terrain topography. A discussion of the potentials of tomographic imaging using the future spaceborne mission BIOMASS is provided in section 7. Conclusions are drawn in section 8 .

\section{Synthetic Aperture Radar Tomography}

The expression Synthetic Aperture Radar (SAR) Tomography (TomoSAR) is generally used to indicate a microwave imaging technology to focus the illuminated scatterers in 3D space by processing data from multiple SAR acquisitions (Reigber and Moreira, 2000). SAR tomographic imaging has been receiving increasing attention in the last years by different research groups, including application fields such as 3D urban scenes, snow, ice sheets, glaciers, and of course forested areas (Reigber and Moreira, 2000), (Tebaldini, 2009), (Frey and Meier, 2011a), 
(Mariotti d'Alessandro and Tebaldini., 2012), (Ho Tong Minh et al., 2014a), (Banda et al., 2016), (Rekioua et al., 2017) , (Tebaldini et al., 2016b), (Yitayew et al., 2017).

The rationale of TomoSAR is easily understood by considering it as an extension of SAR imaging from 2D to 3D. Conventional SAR systems transmit short pulses and receive the echoes backscattered by the illuminated targets along a single flight line, i.e.: a 1D synthetic aperture in the SAR jargon. In this way, the received signal can be focused through digital signal processing techniques to produce a 2D image of the illuminated area, where targets are resolved in the range/azimuth plane (Curlander and McDonough, 1991). TomoSAR imaging is based on the collection of multiple flight lines, i.e.: a $2 \mathrm{D}$ synthetic aperture. This allows focusing the received signal not only in the range/azimuth plane, as in conventional 2D SAR imaging, but also in elevation. A sketch of this concept is shown in figure 2, where TomoSAR voxels are represented by the light-blue ellipses.

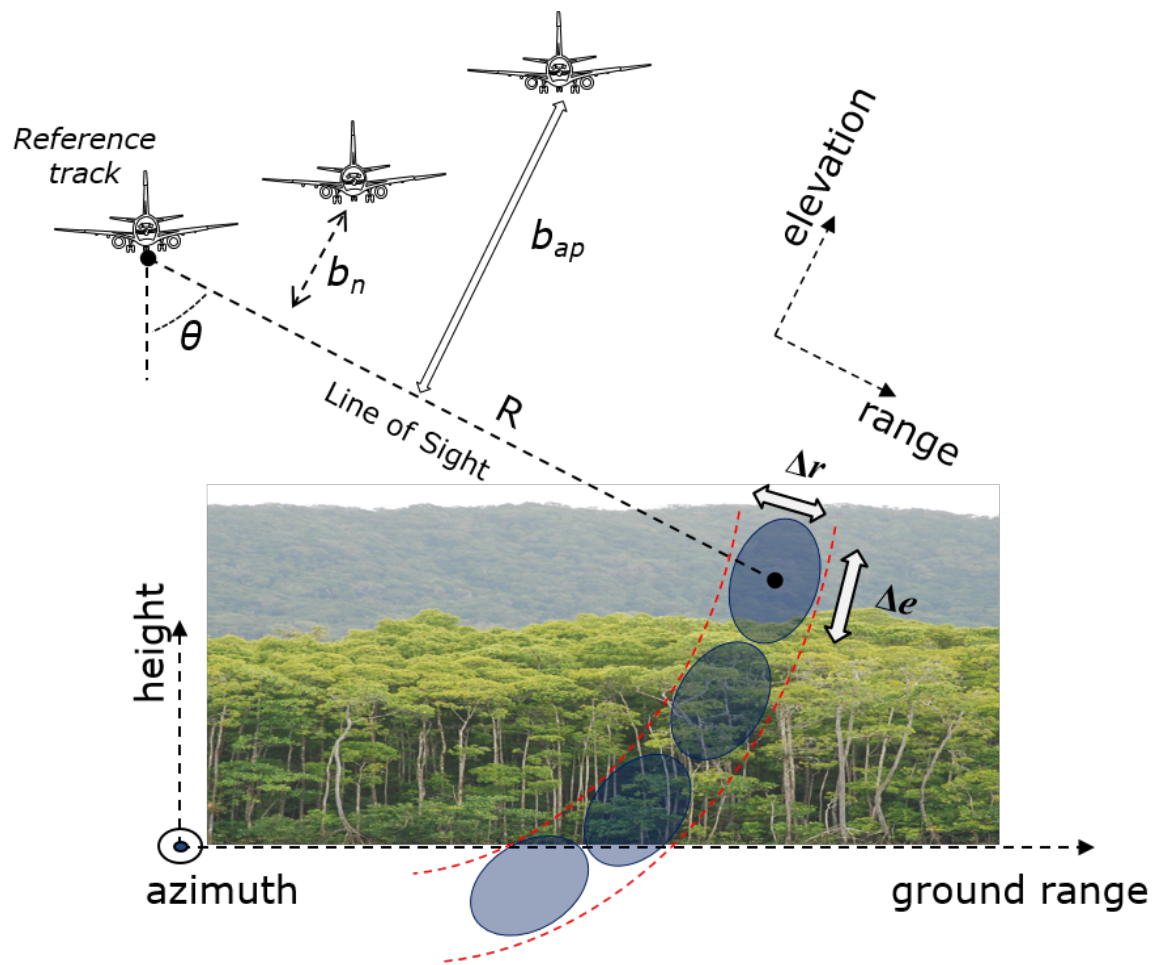

Figure 2: TomOSAR geometry and tomographic voxels in the height/ground range plane. The interferometric baseline $b_{n}$ is defined as the projection of the vector connecting each sensor to the one chosen as common reference onto the normal to the Line of Sight of the Radar, i..e: the direction connecting the reference sensor to the target. Baseline aperture $b_{a p}$ is the total span of the available interferometric baselines.

The geometrical resolution in range and azimuth direction is the same as conventional 2D SAR, that is:

$$
\begin{aligned}
& \Delta r=\frac{c}{2 B} \\
& \Delta x=\frac{\lambda R}{2 L_{S}}
\end{aligned}
$$

where: $r$ and $x$ indicate range and azimuth, respectively, $c$ is the wave velocity in vacuum, $B$ is the pulse bandwidth, $\lambda$ is the carrier wavelength, $L_{s}$ is the 1D synthetic aperture length (in azimuth), and $R$ is the stand-off distance from the imaged target.

Resolution in elevation depends on the total length of the synthetic aperture in elevation, usually referred to as baseline aperture (Bamler and Hartl, 1998). In formula:

$$
\Delta e=\frac{\lambda R}{2 b_{a p}}
$$


where $e$ indicates elevation and $b_{a p}$ is the total baseline aperture. Vertical resolution is roughly obtained by taking the voxel projection along the vertical resolution, that is:

$$
\Delta z=\Delta e \cdot \sin (\theta)=\frac{\lambda R}{2 \Delta b} \cdot \sin (\theta)
$$

where $\theta$ is the incidence angle (Tebaldini et al., 2016). A real-world example is provided in figure 3, which shows two tomographic sections that represent the tropical forest at La Lopé, Gabon, as seen at P-Band. In both panels, the color scale is proportional to signal intensity (blue $=$ low, red $=$ high), and the superimposed white line indicates terrain topography from Lidar measurements. The two panels were obtained by processing a stack of 10 P-Band airborne SAR images acquired by DLR during the ESA campaign AFRISAR (AfriSAR, 2017). In this case, vertical resolution ranges from approximately 8 to $15 \mathrm{~m}$ from near to far range.

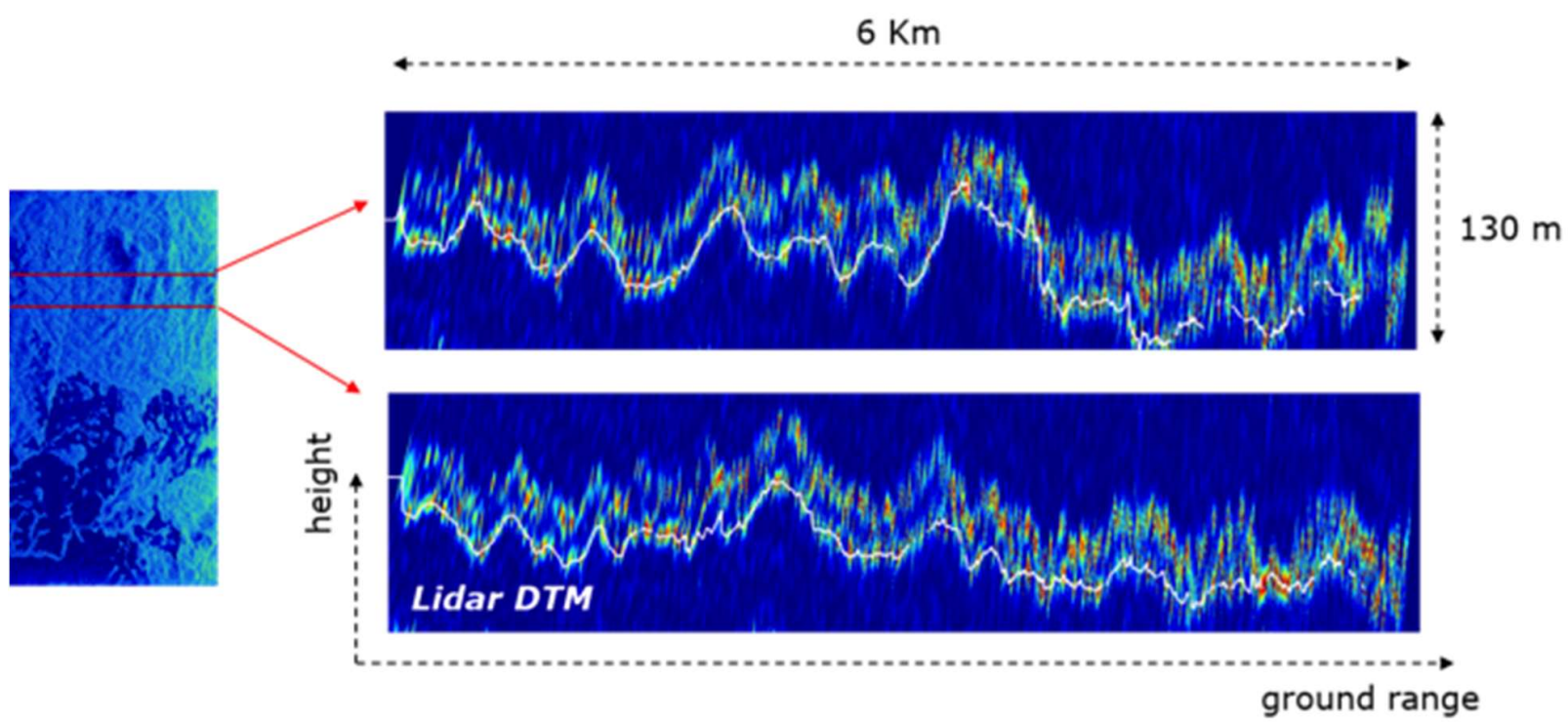

Figure 3: Two tomographic vertical sections of the tropical forest at La Lopé, Gabon. The small image on the left represent a SAR image of the same area, where the two red lines indicate the position of the two tomographic sections on the right. The color scale is proportional to signal intensity (blue = low, red = high). The superimposed white line indicates terrain topography, as obtained by Lidar measurements. Data: AfriSAR at P-Band. Data acquisition by DLR. Tomographic processing by PoliMi.

\section{a. Models and algorithms for SAR Tomography}

A focused SAR image can be generally linked to the vertical distribution of the illuminated scatterers through expressions that account for the distance between scattering elements and the flight trajectory. Assuming approximately parallel trajectories flown along the x-axis, SAR data can be expressed by the 2D model (Bamler and Hartl, 1998), (Tebaldini et al., 2016):

$$
I_{n}=\int s(y, z) \cdot \exp \left(j \frac{4 \pi}{\lambda} R_{n}(y, z)\right) d y d z
$$

Where: $I_{n}$ is a complex-valued pixel from the SAR image acquired along the $n$-th trajectory, $s(y, z)$ represent individual scattering elements in the height/ground range plane, $R_{n}$ is the distance from the scattering element at $(y, z)$ to the Radar sensor in the $n$-th trajectory. The integral in equation (5) is limited to the circular crown of radius $R$, thickness $\Delta r$, and centered on the $n$-th trajectory, as shown by the red dashed lines in figure 2 (Bamler and Hartl, 1998), (Tebaldini et al., 2016). A convenient approximation to equation (5) is obtained by expanding the expression of $R_{n}$ at first order about a reference position, see in particular (Tebaldini et al, 2016), yielding:

$$
I_{n}=\int P(e) \cdot \exp \left(j \frac{4 \pi}{\lambda} \frac{b_{n}}{R} \cdot e\right) d e
$$

Where $e$ is elevation, $P(e)$ is the projection of $s(y, z)$ along the elevation axis, and $b_{n}$ is the interferometric baseline, as shown in figure 2. Equation (6) provides an immediate comprehension on the basic principle of SAR Tomography. Indeed, by defining the elevation wavenumber as (Tebaldini et al, 2016): 


$$
K_{n}=\frac{4 \pi}{\lambda R} b_{n}
$$

it is immediate to see that equation (6) states that the SAR data $I_{n}$ are linked to the distribution of scattering elements along elevation $P(e)$ via a Fourier transform. It then follows that $P(e)$ can be simply retrieved by taking the (inverse) Fourier transform of SAR data with respect to the interferometric baseline, thus adding one dimension w.r.t. conventional SAR imaging (Reigber and Moreira, 2000), (Tebaldini, 2010), (Tebaldini et al., 2016).

Following standard arguments from Fourier analysis, equations (6) and (7) also provide an easy way to assess the performance of tomographic imaging depending on the distribution of available interferometric baselines $b_{n}$. In the first place, resolution in elevation is obtained by taking the inverse of the range of elevation wavenumber (divided by $2 \pi$ ), leading to equation (3). Beside resolution, the other fundamental parameter for assessing the quality of tomographic is height of ambiguity, $z_{a m b}$, which represents the distance from a target along the vertical direction at which artifacts appear due to finite sampling in the wavenumber domain. By assuming a uniform baseline distribution of the form $b_{n}=n \cdot \Delta b$ one gets that wavenumbers are sampled by $\Delta K=\frac{4 \pi}{\lambda R} \Delta b$, hence the ambiguous height interval is:

$$
z_{a m b}=\frac{\lambda R}{2 \Delta b} \cdot \sin (\theta)
$$

The fundamental requirement for correct tomographic imaging of forested area is that the height of ambiguity $z_{a m b}$ is larger than forest height. In designing a tomographic survey, it is good practice to choose a baseline sampling $\Delta b$ such that the height of ambiguity is roughly twice that of forest height. The number of passes is then easily obtained by taking the ration between equations (8) and (4), or equivalently between baseline sampling $\Delta b$ and baseline aperture $b_{a p}$.

A large variety of approaches for tomographic processing is found in literature. The most general and accurate approaches to tomographic imaging are obtained as 3D time domain back projection, which allow taking into account strongly irregular trajectories and very large baselines (Frey and Meyer, 2010), (Tebaldini et al., 2016). In most cases, however, tomographic imaging can be carried out by decoupling focusing in the range-azimuth plane from focusing in elevation. This approach allows casting tomographic processing in terms of a one-dimensional problem, as depicted in equation (6), resulting in a substantial advantage in terms of computational burden and enabling the employment of a large variety of techniques from spectral analysis, (Gini et al., 2005), (Budillon et al., 2011), (Zhu and Bamler, 2012), (Aguilera et al., 2013), (Huang et al., 2017). A most interesting aspect of these techniques is that they provide super-resolution capabilities, that is, the capability to resolve targets at a finer resolution than the one expressed in (4). Unfortunately, super-resolution is achieved at the expense of radiometric accuracy, which prevents the application of super-resolution techniques in a general context (Gini et al., 2005), (Pardini and Papathanassiou, 2017). Finally, a fundamental requirement to enable tomographic focusing is that the knowledge about the position of the Radar along the trajectory in all flights is accurate enough to predict variations of the distance travelled by the wave to within an accuracy much better than the system wavelength. This accuracy is seldom met by current navigational systems concerning the location of one flight line with respect to another. As a result, SAR images are affected by space-varying phase disturbances, commonly referred to as phase screens, which produce blurring (Tebaldini and Monti Guarnieri, 2010), (Tebaldini et al., 2016). For this reason, a preprocessing phase calibration step is quite often required before tomographic focusing (Tebaldini and Monti Guarnieri, 2010), (Tebaldini et al., 2016).

\section{An introduction to forest scattering at microwave regime}

A most relevant feature of low frequency microwaves is the capability to penetrate through the whole vegetation layer down to underlying ground. As the wave travels through the vegetation, it interacts with leaves, branches, tree trunks, and finally the terrain, generating new waves that are scattered in all directions and further interact with the vegetation and the terrain. As a result, the Radar signal can be modeled as the result of different scattering mechanisms (SM). Consistent with a large part of the literature, we will assume here four SMs, as pictorially depicted in figure 4 (Sarabandi, 1992), (Ulaby et al., 1998), (Cloude and Pottier, 1997), (Freeman and Durden, 1998), (Treuhaft and Siqueira, 2000), (Papathanassiou and Cloude, 2001), (Smith-Jonforsen et al., 2007):

i) Backscattering from the tree canopies. This SM is the result of direct backscattering from woody elements within the vegetation layer. Accordingly, it provides the most direct information about the vertical structure of the vegetation. The resulting signal is depolarized, hence present with varying intensity in all polarimetric channels. 
ii) Backscattering from the terrain. This SM gives rise to a strongly polarized signal, for which the intensity is much larger in like-polarized returns than in cross-polarized ones. Especially at PBand, terrain scattering is weak compared to forest scattering, and can usually be neglected.

iii) Double-bounce scattering from trunk-ground interactions. This SM occurs as a result of the two specular reflections of the wave onto the tree trunks and the terrain, or vice-versa. After the second reflection, the signal is conveyed back to the Radar at varying intensity, depending on the tree characteristics and on topographic slope. Intensity is maximal when terrain topography is flat, whereas it tends to vanish on both positive and negative slopes (Smith-Jonforsen et al., 2007). It may be shown through geometrical arguments that this SM may be regarded as an equivalent point-like scatterer located at the tree trunk base. Hence, it appears at the terrain level in tomographic images. Another peculiar trait of trunk-ground scattering is found in the phase difference between $\mathrm{HH}$ and VV polarizations, which typically assumes values ranging from about $90^{\circ}$ to $180^{\circ}$, depending on the Fresnel coefficients of the terrain and the tree trunks (Freeman and Durden, 1998). Assuming flat topography, trunkground scattering is not expected to contribute at HV polarization (Freeman and Durden, 1998).

iv) Double bounce scattering from canopy-ground interactions. This SM results from the waves bouncing off the ground in the direction of the Radar after being scattered downwards by vegetationelements within the canopy (woody elements at $\mathrm{P}$ band). Canopy-ground scattering appears at the terrain level in tomographic images, as discussed in the case of trunk-ground scattering. The resulting signal is depolarized, hence present with varying intensity in all polarimetric channels.

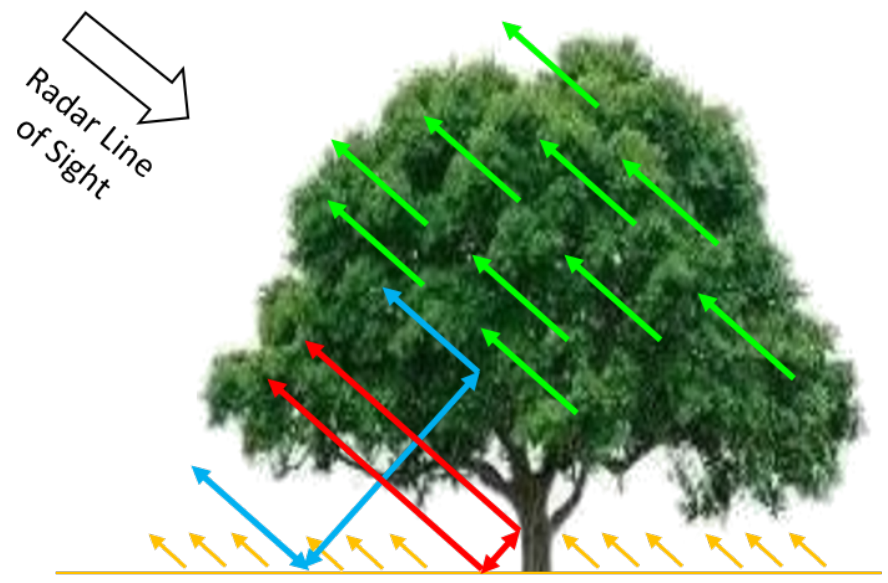

Figure 4: Pictorial view of the four main scattering mechanisms arising in forested areas. Light green: canopy backscattering. Yellow: terrain backscattering. Red: trunk-ground double bounce scattering. Blue: canopy-ground double bounce scattering.

\section{Sensitivity to forest structure}

The first tomographic campaign carried out in the frame of BIOMASS studies is BIOSAR 2007, which took place at the Remningstorp forest site, in southern Sweden (BIOSAR, 2008). Prevailing tree species are Norway spruce Scots pine and birch. The dominant soil type is till with a field layer, when present, of blueberry and narrow thinned grass. Tree heights are on the order of $20 \mathrm{~m}$, with emergents up to $30 \mathrm{~m}$. The topography is fairly flat, terrain elevation above sea level ranging between 120 and $145 \mathrm{~m}$. The acquisition campaign was carried out by DLR from March to May 2007, and comprises 14 fully polarimetric P-Band SAR images. The horizontal baseline spacing is approximately $10 \mathrm{~m}$, resulting in a maximum horizontal baseline of approximately $80 \mathrm{~m}$ and a vertical resolution ranging from approximately $10 \mathrm{~m}$ to $40 \mathrm{~m}$ from near to far range.

Two tomographic vertical sections of the Remningstorp forest are shown in the right-hand part of figure 5. The two vertical sections are referred to the same area, but were obtained by processing different polarimetric channels. In both panels, the color scale is proportional to signal intensity (blue $=$ low, red $=$ high), and the superimposed lines indicates terrain topography (black) and canopy height (green) obtained from Lidar measurements. Looking at the vertical section at HH (top panel), the first feature that immediately catches the eye is that the highest levels of signal intensity (red areas) are found at terrain level, whereas the signal from the forest canopy is nearly undetectable. Consistently with the discussion in section 3 , this behavior clearly indicates that the signal in like-polarized channels is dominated by trunk-ground scattering, as also 
further confirmed by polarimetric analysis in (Tebaldini, 2009) and (Tebaldini, 2010). The most surprising result, however, is that a similar behavior is observed at HV (bottom panel of figure 5), for which the brightest areas are again found at the ground level, and the signal scattered from the forest canopies is only barely detectable, indicating that double-bounce scattering is present at HV as well (Tebaldini, 2010).
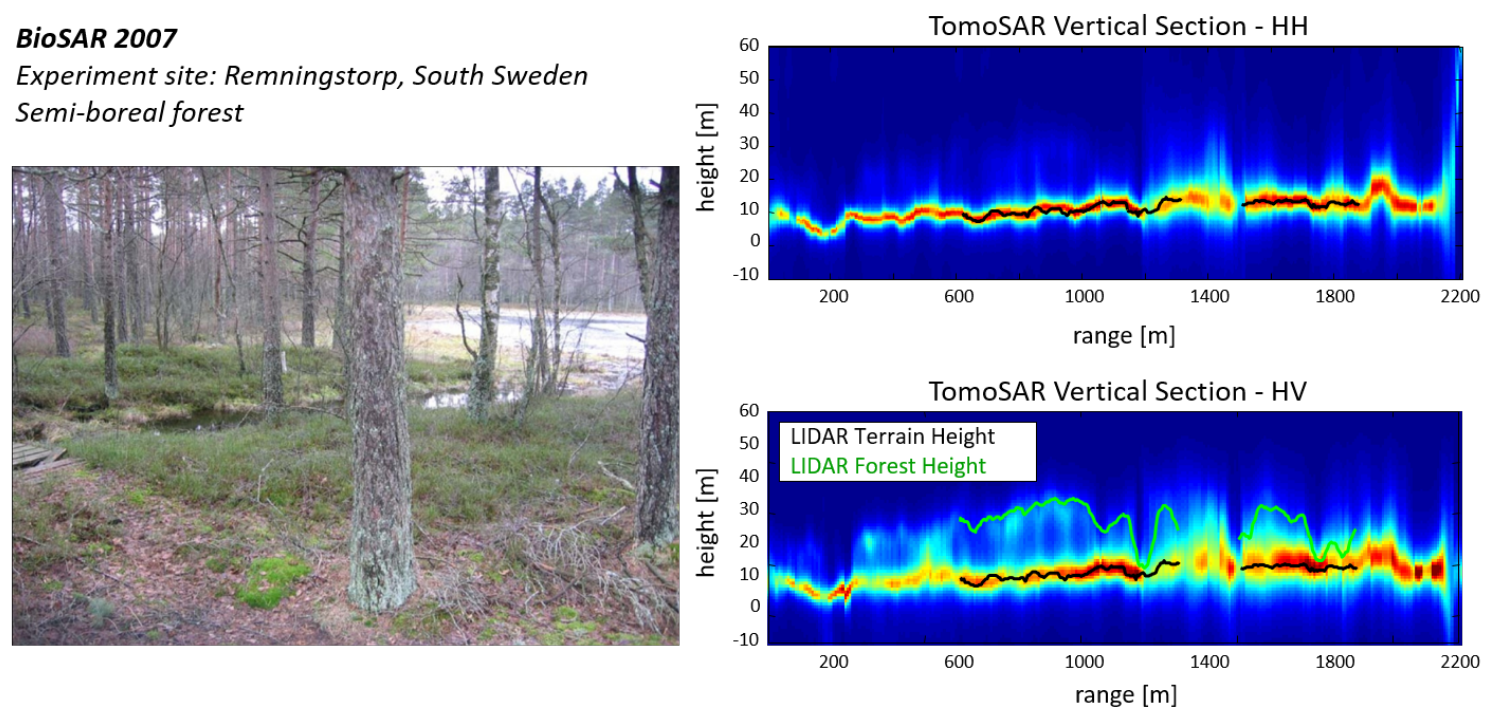

Figure 5: Tomographic vertical sections of the semi-boreal forest at Remningstorp, Southern Sweden. The color scale is proportional to signal intensity (blue $=$ low, red $=$ high). For visualization purposes, both panels were normalized such that the sum along each column is unitary. The superimposed lines indicates terrain topography and forest height, as obtained by Lidar measurements. Data: BioSAR 2007, $P$-Band. Data acquisition by DLR.

The subsequent tomographic campaign on boreal forest was BIOSAR 2008, flown in Northern Sweden at P-Band and LBand (BIOSAR, 2009). Tomographic data from BIOSAR 2008 confirmed the intuitions of BIOSAR 2007, revealing the presence of double bounce scattering and allowing to study their dependence on topographic slope (Tebaldini and Rocca, 2012).

The first tomographic campaign focused on tropical areas was TropiSAR, which was flown in summer 2009 at the two tropical sites of Paracou and Nouragues, French Guiana (TropiSAR, 2011). The Paracou site was the first to be investigated using tomography. The forest at this site is classified as a lowland moist forest, with approximately 140-200 tree species per hectare. The tree top height reaches $45 \mathrm{~m}$, with an average canopy height of about $30 \mathrm{~m}$. The acquisition campaign was carried out by ONERA. The tomographic data-set at Paracou and comprises 6 fully polarimetric P-Band SAR images. Vertical resolution is approximately $20 \mathrm{~m}$.

The right-hand panels of figure 6 reports an $\mathrm{HH}$ and an HV tomographic vertical section of the forest in Paracou. For visualization purposes both panels were resampled such that the terrain level is 0 . It is immediate to note how different these sections look as compared to those from Remningstorp. Indeed, scattering from the forest canopies are well detectable at both polarizations. At HV, one can even see that the brightest areas are often found at the canopy level, rather than on the ground. Yet, it is also to be remarked that does not vanish in correspondence with the terrain level, demonstrating that the wave is actually penetrating through the whole vegetation layer down to the ground (Mariotti d'Alessandro et al., 2013).

In conclusion, although the results in this section have only been discussed qualitatively, they demonstrate a most important point: SAR tomography is highly sensitive to forest structure. An in-depth assessment of the role of SAR tomography in the remote sensing of forested areas will be presented in the next sections. 
TropiSAR 2009

Experiment site: Paracou, French Guiana Tropical forest

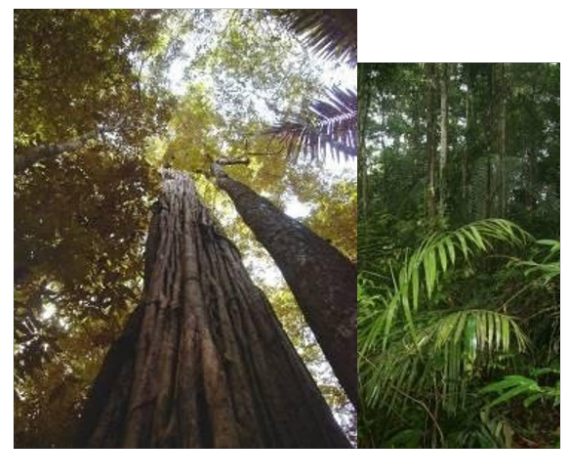

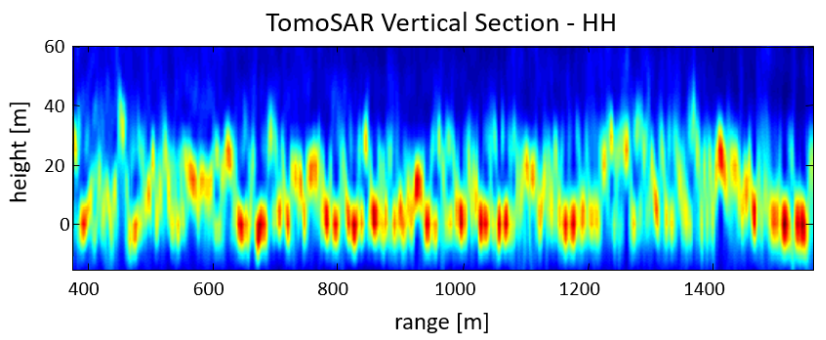

TomoSAR Vertical Section - HV

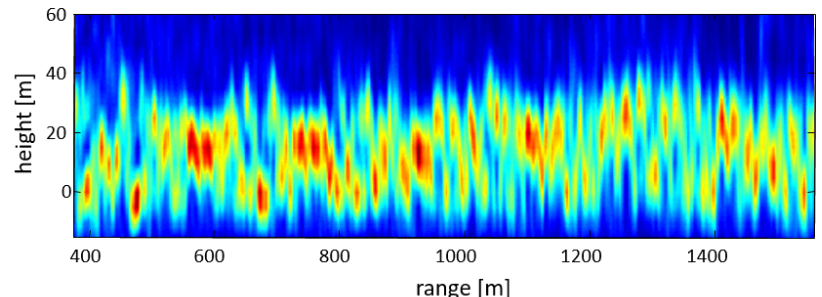

Figure 6: Tomographic vertical sections of the semi-boreal forest at Paracou, French Guiana. The color scale is proportional to signal intensity (blue =low, red = high). For visualization purposes, both panels were normalized such that the sum along each column is unitary, and resampled such that terrain level is $0 \mathrm{~m}$. Data: TropiSAR 2009, P-Band. Data acquisition by ONERA.

\section{The link to forest Above Ground Biomass}

Aboveground biomass ( $\mathrm{AGB}$, in $\mathrm{Mg}$ of dry matter per hectare or in $\mathrm{t} / \mathrm{ha}$ ) is the mass of vegetation standing aboveground. It is a key quantity as it constitutes an important ecosystem service, but is also a major store of carbon in the biosphere. The first works that studied the link between SAR tomography and AGB in a quantitative manner are those by Ho Tong Minh et al. (Ho Tong Minh et al., 2014, 2016). Both papers are based on an analysis of the correlation between forest AGB available from in situ surveys and the intensity of tomographic horizontal sections corresponding to different heights w.r.t. to the terrain. The analyzed data-sets are the ones collected by ONERA during the TropiSAR campaign (TropiSAR, 2011). The Paracou site was investigated in (Ho Tong Minh et al., 2014), whereas the Nouragues site was studied in (Ho Tong Minh et al., 2016).

The Paracou site is located in a lowland tropical rain forest near Sinnamary. Terrain elevation is between 5 and $50 \mathrm{~m}$, and mean annual temperature is $26^{\circ} \mathrm{C}$, with an annual range of $1{ }^{\circ} \mathrm{C}-1.5^{\circ} \mathrm{C}$. The landscape is characterized by a relatively flat terrain, which is dissected by narrow streams. As mentioned in the last section, the forest in Paracou is classified as a lowland moist forest. The tree flora at Paracou exceeds 550 woody species attaining $2 \mathrm{~cm}$ diameter at breast height (DBH) have been described in (Molino and Sabatier, 2001), and a single hectare of forest may harbor 140-200 tree species. Top-ofcanopy height reaches up to $45 \mathrm{~m}$ with the average value around $30 \mathrm{~m}$. The Nouragues Ecological Research Station, is located $120 \mathrm{~km}$ south of Cayenne, French Guiana, and was established in 1986. This area is a protected natural reserve characterized by a lowland moist tropical rainforest. Recent floristic censuses have recorded over 660 species of trees above $10 \mathrm{~cm}$ in trunk diameter (DBH) in a 12-ha plot. The landscape is a succession of small hills, between $60-120 \mathrm{~m}$ asl covered by a pristine forest. One prominent feature of the landscape is the presence of a granitic hill, called inselberg, with no vegetation at the top. Top-of-canopy height reaches up to $55 \mathrm{~m}$ with the average value around $35 \mathrm{~m}$.

In-situ forest AGB measurements were available in Paracou from 16 permanent plots established since 1984, and in Nouragues from two large and long term permanent plots established in 1992-1994 and regularly surveyed to the present (Ho Tong Minh et al., 2016). At both test sites, plots were subdivided in $100 \times 100 \mathrm{~m}$ subplots (1 ha), resulting in 85 plots in Paracou and 22 in Nouragues (Ho Tong Minh et al., 2016).

Tomographic data consisted of fully polarimetric P-Band SAR images acquired on 14 August 2009 in Nouragues (5 flight tracks) and ten days later in Paracou (6 flight tracks). Importantly, the tomographic flight lines were displaced in a vertical plane rather than in a horizontal plane, which helped limiting spatial variations of vertical resolution across the scene swath 
(Dubois-Fernandez et al., 2012). This allowed both forest sites to be imaged at an approximately constant vertical resolution of $20 \mathrm{~m}$ without the need for super-resolution imaging techniques, and thus preserving radiometric accuracy (Mariotti d'Alessandro et al., 2013), (Ho Tong Minh et al., 2016).
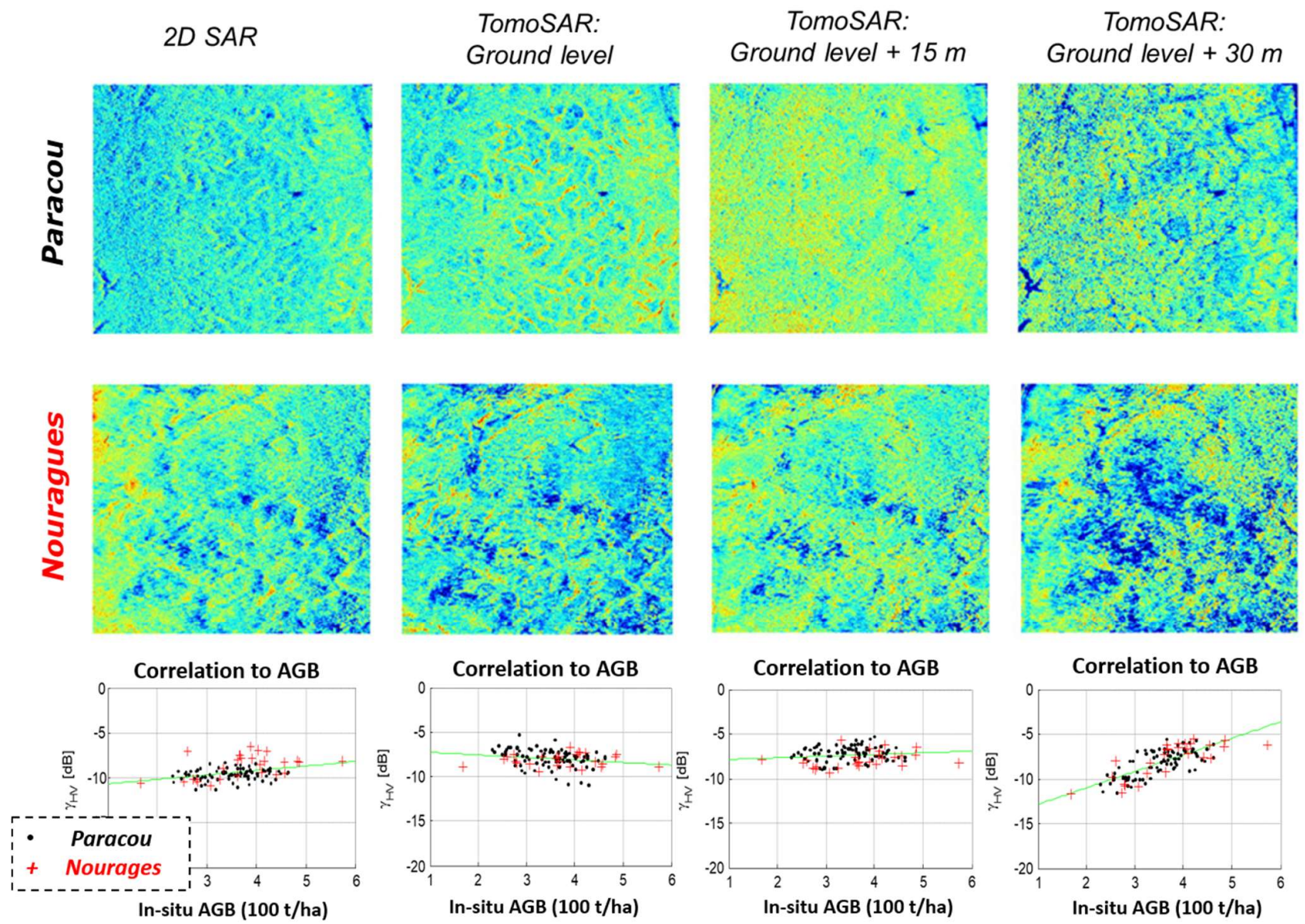

Figure 7: Correlation between SAR and TomoSAR intensities and AGB at Paracou and Nouragues, French Guiana. Top two rows: 2D SAR intensity (leftmost panel) and TomoSAR intensities from ground level, $15 \mathrm{~m}$ and $30 \mathrm{~m}$ above ground level for Paracou and Nouragues. Polarization is HV in all panels. Bottom row: scatterplots between intensity and AGB (as derived from in situ observations). The size of each plot is approximately 1 ha. Pictures drawn from (Ho Tong Minh et al., 2014a, 2016)

A synthesis of the analysis carried out in (Ho Tong Minh et al., 2014, 2016) is presented in figure 7. The main results are summarized as follows:
- 2D SAR intensity is poorly correlated with AGB
- Tomographic intensity at $0 \mathrm{~m}$ is poorly and negatively correlated with AGB
- Tomographic intensity at $15 \mathrm{~m}$ is poorly correlated with AGB
- Tomographic intensity at $30 \mathrm{~m}$ is highly correlated with AGB. The observed sensitivity is $\approx 50 \mathrm{Mg} / \mathrm{ha}$ per $\mathrm{dB}$.

Interestingly, the relation between TomoSAR intensity at $30 \mathrm{~m}$ and AGB becomes increasingly accurate by aggregating plots at a larger scale, and produces a correlation coefficient of 0.97 for plot sizes of about 6 ha.

Based on these results, an inversion procedure was introduced in (Ho Tong Minh et al, 2014a) to retrieve AGB by assuming linear dependency on HV tomographic intensity at $30 \mathrm{~m}$. The inversion was trained by using few 1 ha samples, and validated with the remaining, resulting in a final total AGB error (RMSE) lower than $10 \%$ at 1 ha resolution This approach was later extended in (Ho Tong Minh et al, 2016), where a cross validation was assessed using training plots from 
Nouragues and validation plots from Paracou, and vice-versa, resulting in a total AGB error at the two sites around 16-18\% at 1 ha resolution, as shown in figure 8.
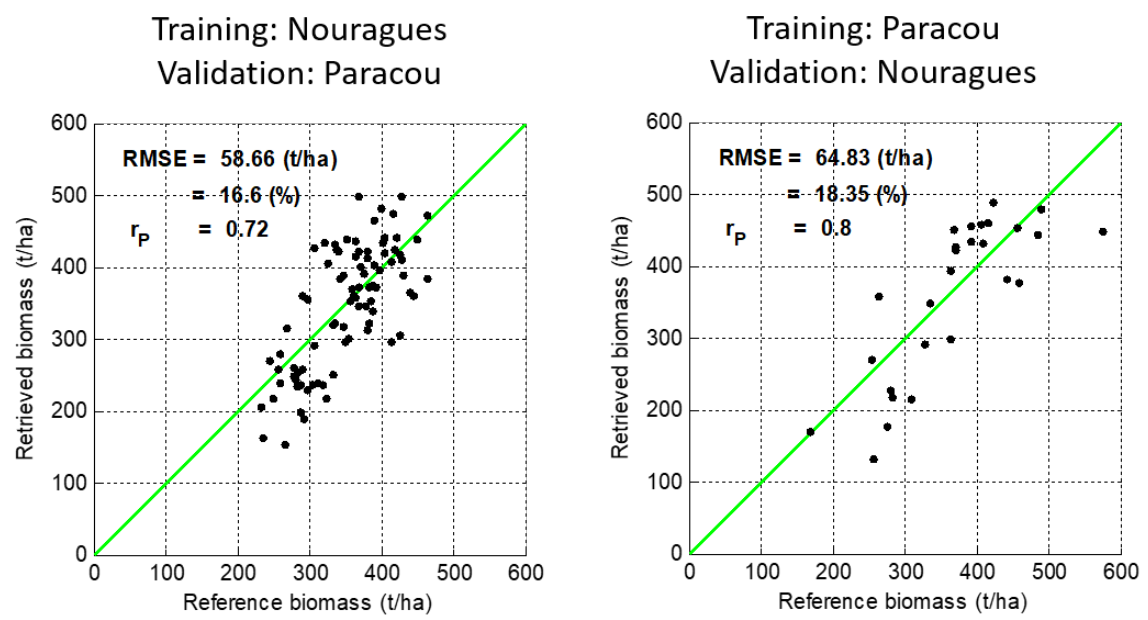

Figure 8: TomoSAR biomass retrieval result based on cross-validations: comparison of retrieved AGB and in-situ AGB. Left: Training in Nouragues and validation in Paracou. Right: Training in Paracou and Validation in Nouragues. Picture drawn from (Ho Tong Minh et al., 2016).

After TropiSAR, the next campaign focused on tropical forests was AfriSAR, which was carried out in Gabon in 2015 and 2016 (AfriSAR, 2017). The campaign was shared between ONERA (dry season, July 2015) and DLR (wet season, February 2016), and included tomographic acquisitions at a vertical resolution of about $10 \mathrm{~m}$ to $15 \mathrm{~m}$ at the forest sites of Lopé, Mondah, Mabounié, and Rabi. These four forest sites are characterized by different physical forest structure types, biomass levels, growth stages, and different levels and kinds of disturbance. All sites contain ground data (permanent tree inventories) together with aerial lidar scanning of the regions of interest from which reference biomass data have been generated (Labrière et al., 2018). Lopé is located $250 \mathrm{~km}$ east of the Libreville airport, and it is characterized by a mosaic between forests and savannas. Biomass ranges between approximately $50 \mathrm{t} / \mathrm{ha}$ of woody savannah and $600 \mathrm{t} / \mathrm{ha}$. Two tomographic vertical sections of the Lopé forest sites are shown in section 2, figure 3 . Mondah is located $25 \mathrm{~km}$ North of the Libreville airport. It is a relatively young forest with high variability of density, with also some degradation due to the proximity to the city. Tree height can also be higher than 40m. Mabounié is located $180 \mathrm{~km}$ South of the Libreville airport. The landscape is mostly forested (including swamp and temporarily flooded areas), and most areas are rather hilly (altitude ranges between 25-230 m asl). Due to the presence of rare earths, mining exploration took place during the last decades, and many degraded areas are still visible. Rabi is located $260 \mathrm{~km}$ South from the Libreville airport. The area of interest contains a 25 ha permanent plot maintained by the Smithsonian Institute, for which extensive ground measurements are available. Next to this plot, an oil extraction area is present around which many degraded areas can be found.

Tomographic data have been generated using data acquired by ONERA at the sites of Lopé, Mondah, and Rabi, and correlated to in-situ AGB following the same methodology as in (Ho Tong Minh, 2014a). Results from AfriSAR are shown in figure 9, where we overlay those from TropiSAR for reference. Crucially, the results are observed to be consistent with those obtained in French Guiana, preserving a similar sensitivity and accuracy for AGB values larger than 200 t/ha.

Accordingly, all the results obtained so far at 5 tropical forest sites in South America and Equatorial Africa clearly indicate that tomographic intensity at $30 \mathrm{~m}$ is dramatically more correlated with AGB than 2D SAR intensity. The observed sensitivity was found to be about $50 \mathrm{Mg} /$ ha per $\mathrm{dB}$ across the range of AGB values from about 200 to 500 tons/ha.

Understanding the reasons behind this empirical result is of primary relevance to achieve a more complete understanding of forest scattering at $\mathrm{P}$ band. This, in turn, is of crucial importance in the context of the BIOMASS mission. A better understanding is expected to result in better algorithms for AGB retrieval, and possibly limit as much as possible the need for external data for calibration. In the remainder of this section, we discuss two possible reasons, of both ecological and electromagnetic nature, that could help understand the physics underlying the observations:

- $30 \mathrm{~m}$ is a biophysically relevant height in dense tropical forests 
Ground scattering acts as a noise factor on 2D SAR intensity, limiting its sensitivity to AGB. This disturbing factor is most efficiently cancelled out in tomographic intensity at $30 \mathrm{~m}$, which would explain the dramatic increase in sensitivity.

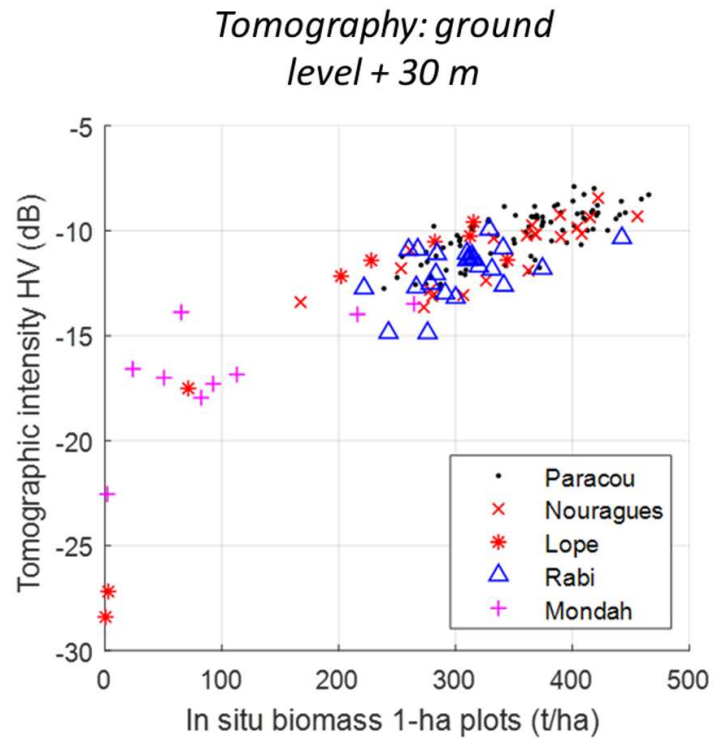

Figure 9: Plot of TomoSAR intensity at $30 \mathrm{~m}$ against AGB at the 5 tropical forest sites in South America and Equatorial Africa.

\section{a. The ecological reason: the role of the $30 \mathrm{~m}$ layer}

Considering the vertical resolution of the data considered in this paper, tomographic intensity at $30 \mathrm{~m}$ accounts approximately for scatterers in the layer from $20 \mathrm{~m}$ to $40 \mathrm{~m}$ above the terrain. Accordingly, the question is whether there is any biophysical reason connecting this layer to total AGB.

To answer this question, we assume a simple structural model of tropical rain forests, which accounts for five layers: the overstorey, the main canopy, the understory, the shrub layer, and the forest floor. This structure is classically observed in aerial lidar scanning, and even more precisely using terrestrial lidar scanning. The overstorey refers to the crowns of emergent trees which are above the rest of the canopy (above 40m). The canopy is the dense ceiling of closely packed trees and their branches, centered at about $30 \mathrm{~m}$, while the understory denotes more widely spaced, smaller tree species and young individuals that form a broken layer below the canopy (below $20 \mathrm{~m}$ ). The shrub layer is characterized by shrubby species and young trees that grow only 2-6 $\mathrm{m}$ off the forest floor.

The canopy layer and is the principal site for the interchange of heat, water vapor, and atmospheric gases. Under the canopy, there is little direct sunlight due to the extinction of the light through the canopy layer. For these reasons, it is expected that the layer from $20 \mathrm{~m}$ to $40 \mathrm{~m}$ contains a major part of the leaves, and a large proportion of woody elements, including trunks and most of the branches (primary, secondary, and higher order) that contribute to the total AGB. Still, the question remains whether the fraction of biomass contained in the $30 \mathrm{~m}$ layer is actually representative of the total AGB.

A first answer to this question was given in (Ho Tong Minh et al., 2014a) by assuming a forest structure as derived from the TROLL model (Chave, 1999; Maréchaux and Chave 2017), which is a spatially explicit forest growth simulator designed to study structural, successional and spatial patterns in natural tropical forests. The model includes competition for light, treefall gap formation and recruitment, which are the critical phenomena in the morphology of tropical forests. The parameters of the model for the species groups have been determined using field data in French Guiana. As a result, an area of $400 \mathrm{mx} 400 \mathrm{~m}$ was generated, from which biomass between $20 \mathrm{~m}$ and $40 \mathrm{~m}$ was extracted and compared to total AGB. Simulations showed that biomass contained in the $20-40 \mathrm{~m}$ layer is about $40 \%$ of the total AGB, and that it is strongly correlated $(\mathrm{rp}=0.92)$ to total AGB over the whole range of AGB from 250 to $700 \mathrm{t} / \mathrm{ha}$ (Ho Tong Minh et al., 2014a). 


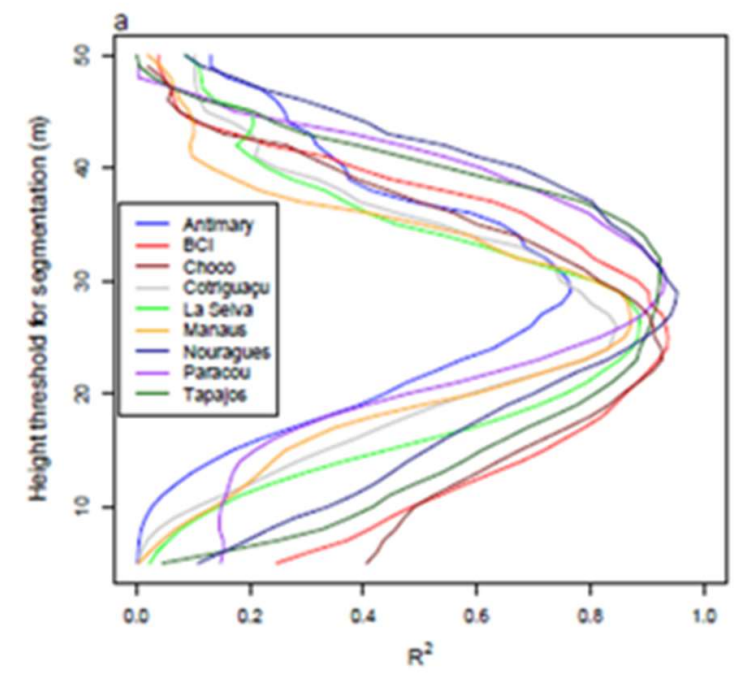

Figure 10: Correlation between AGB and the area occupied at different heights by large trees (as derived from Lidar) in 9 tropical rainforest sites in South America. Picture drawn from (Meyer et al., 2018).

Most interestingly, this result is confirmed by the recent reanalysis of lidar images at 9 tropical sites in South America (Meyer et al., 2018), which analyzes the correlation between AGB and the area occupied at different heights by large trees . Correlation (R2) was found to be maximum at a height of 27-30 $\mathrm{m}$ at all the 9 study sites, as shown in figure 12 .

In conclusion, both ecological modelling and empirical Lidar measurements support the idea that the $30 \mathrm{~m}$ layer does actually play a special role in tropical forests, as the fraction of biomass included in it provides a reliable proxy to total AGB.

\section{b. The EM reason: the role of ground scattering}

The behavior of ground scattering in a tropical forest was thoroughly investigated in (Mariotti d'Alessandro et al., 2013) based on the tomographic P-band dataset acquired by ONERA at the forest site of Paracou, French Guiana.

The analysis in that paper focused on the variation of backscattered intensity and copolar phase (i.e.: the phase between HH and VV) w.r.t. ground range slope, considering both 2D SAR intensity and Tomographic data at ground level, see figure 11.

Figure 11 shows that both the intensity and the copolar phase are modulated by ground range slope. In particular, in flat areas, intensity is seen to increase and the copolar phase approaches $-180^{\circ}$, which is a clear indication of the occurrence of double-bounce scattering from ground-trunk interactions (Mariotti d'Alessandro et al., 2013). With tomographic data, the variation of intensity associated with double-bounce scattering was accurately estimated as about $5 \mathrm{~dB}$ (see the bottom panels of figure 11).

Further analysis based on physical optics showed that the characteristic parameter that rules ground-trunk scattering is not only tree height, but also the length of the base available for ground reflections (Mariotti d'Alessandro et al., 2013), which indicates that this phenomenon is connected to the presence of nearby trees, understory, and undulating topography. The immediate conclusion that can be drawn from this analysis is that, even in a dense tropical forest, double bounce scattering from ground-trunk interactions is relevant on flat areas. Another conclusion is that ground-trunk scattering in tropical forests is strongly connected to local topography, and also to local forest features, such as tree density, and density of the understory. Moreover, although not considered in (Mariotti d'Alessandro et al., 2013), soil moisture and canopy-ground scattering are expected to play a role, as predicted by EM models (Truong-Loi et al., 2015). 


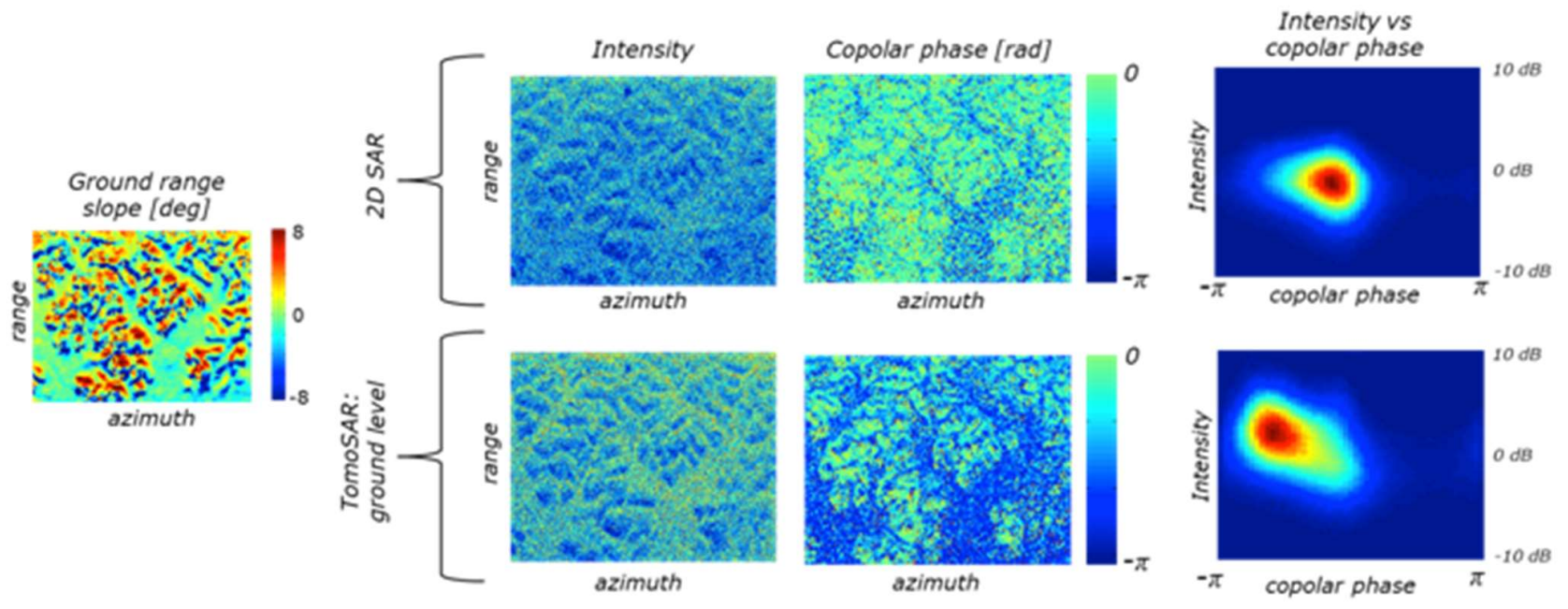

Figure 11: Top row: backscattered intensity, copolar phase, and 2D histogram relating backscattered intensity and copolar phase for the original (i.e.: non-tomographic) SLC data. Bottom row: backscattered intensity, copolar phase, and 2D histogram relating backscattered intensity and copolar phase for tomographic data corresponding to ground level. Leftmost panel: ground range slope: positive valued pixels indicate the terrain is tilted toward the Radar. Picture drawn from (Mariotti d'Alessandro et al., 2013).

These conclusions are consistent with the results in (Ho Tong Minh, 2014, 2016), showing that ground scattering is poorly and negatively correlated to AGB. Indeed, a slight decay of ground scattering with increasing AGB can be explained by assuming that total wave attenuation increases with AGB. However, as noted above, ground scattering is also determined by several other factors, which necessarily weakens the correlation to AGB.

\section{Forest height and terrain topography}

The retrieval of canopy height using SAR tomography has been considered since the early experiments in 2007. The basic principle enabling the use of SAR tomography for this task is immediately understood by considering tomographic vertical sections, such as those in figure 3,5, and 6. Indeed, wave scattering from forested areas is bound to occur between the terrain and the top of the canopy. Hence, canopy height can be retrieved, at least in principle, by tracing the upper envelope in tomographic sections. An advantage of this approach is that it is less computationally expensive than model-based inversion, and can be applied in the absence of a specific model of the forest vertical structure. In the recent literature, this approach has been successfully applied on boreal and tropical forests, using data from BIOSAR 2008 and TropiSAR. Performance was assessed based on a pixel-to-pixel comparison against Lidar measurements, and resulted in an accuracy of about $3 \mathrm{~m}$ at a resolution of $60 \times 60 \mathrm{~m}^{2}$ in the case of boreal forests (Tebaldini and Rocca, 2012) and about $2.5 \mathrm{~m}$ at a resolution of $60 \times 60 \mathrm{~m}^{2}$ in the case of tropical forests (Ho Tong Minh et al., 2016). The achievement of a better accuracy in the latter case is most likely due to the better vertical resolution of TropiSAR data w.r.t. BIOSAR 2008. In figure 12, we report a recent example of the application of this approach to the case of tropical forests using data from AfriSAR. Performance assessment of the TomoSAR height retrieval algorithm is part of an ongoing study.

In addition to forest height, SAR tomography is also being investigated to retrieve a digital terrain model. This task was first considered for the case of boreal forests in (Tebaldini, 2010), where terrain topography was retrieved by assuming a parametric model. In that paper, accuracy was assessed to be about $2 \mathrm{~m}$ by comparison against Lidar measurements of ground elevation (Tebaldini, 2010). In dense tropical areas, terrain topography retrieval was first considered in (Mariotti d'Alessandro and Tebaldini, 2013). In this case, retrieval was obtained by jointly processing tomographic data at different polarizations, according to the procedure introduced in (Tebaldini, 2009). For terrain topography accuracy assessment was not considered in (Mariotti d'Alessandro and Tebaldini, 2012). However that terrain localization was accurate enough to enable the later developments in (Mariotti d'Alessandro et al., 2013), (Ho Tong Minh et al., 2014a), (Ho Tong Minh et al., 2016). A quantitative assessment of the accuracy achievable in tropical areas is part of an ongoing study based on tomographic data from the AfriSAR campaign (Mariotti d'Alessandro and Tebaldini, 2018). Preliminary results are 
encouraging, and support the idea that SAR tomography will be useful in the future as an alternative to Lidar mapping. An example is shown in figure 13.
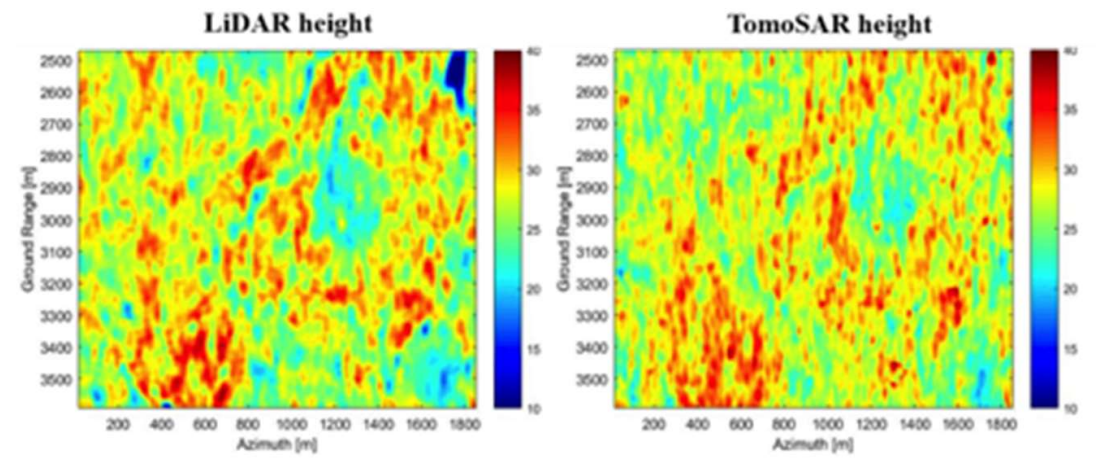

Figure 12: Retrieval of forest height. Left: forest height from Lidar survey. Right: forest height by tracing the envelope of tomographic intensities. Data: AfriSAR P-Band. Data acquisition by DLR.
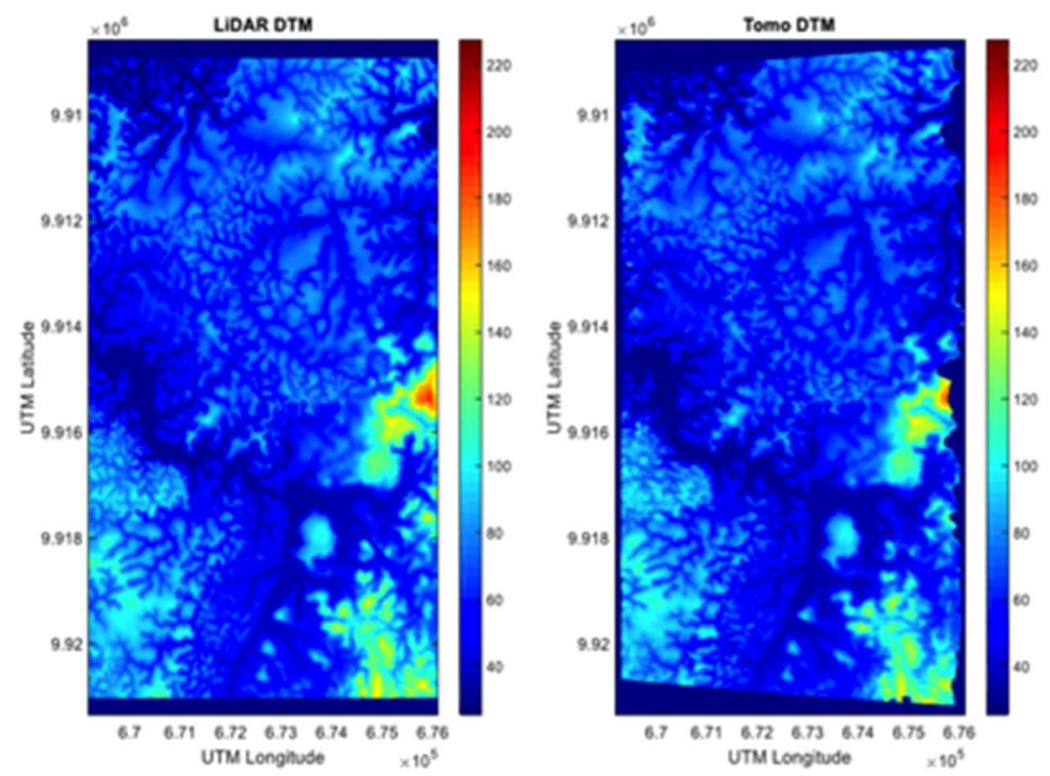

Figure 13: Retrieval of sub-canopy terrain topography. Left: Digital Terrain Model (DLR) from Lidar survey. Right: DTM by SAR tomography. Data: AfriSAR P-Band. Data acquisition by DLR.

\section{BIOMASS Tomography}

BIOMASS was selected in 2013 to be ESA's $7^{\text {th }}$ Earth Explorer Core Mission. The mission primary objective is to generate accurate maps of forest biomass and height at a global scale. BIOMASS will be implemented as a fully polarimetric SAR operating at P-Band, taking advantage of the understorey penetration capabilities of wavelengths (ref BIOMASS). Launch date is currently planned in 2022. The satellite will operate in two different observation phases, referred to as tomographic and interferometric phase, respectively. The tomographic phase will operate during the first 14 months of the mission lifetime. In this phase, the satellite will be orbited to provide 7 consecutive acquisitions per site from slightly different points of view, hence enabling TomoSAR imaging. Geographical coverage during the tomographic phase will be global, and the 7 passes will be acquired with a time lag of 3 days from one another. In the subsequent interferometric phase, the satellite orbits will be modified to achieve faster coverage. This phase will produce 3 consecutive acquisition per site at a revisit time of 3 days, enabling AGB and forest height retrieval by SAR Polarimetry and Polarimetric Interferometry (ref BIOMASS). 
The achievement of radiometrically and geometrically accurate tomographic products in the context of BIOMASS is a challenging task. Indeed, one has to account for several potentially damaging factors w.r.t. the airborne case, including degraded signal to noise ratio, coarser spatial resolution, propagation through the ionosphere, and temporal decorrelation effects due to the fact that the 7 acquisitions needed to implement SAR tomography will be collected in 18 days.

The impact of system range and azimuth resolution has drawn attention since early experiments. Indeed, airborne campaign data provide a resolution on the order of $1 \mathrm{~m}$, whereas BIOMASS will generate data at a resolution of about $10 \mathrm{~m}$ in azimuth and only $25 \mathrm{~m}$ in range, due to the $6 \mathrm{MHz}$ bandwidth limit imposed by ITU regulations (ESA, 2012). This disparity in spatial resolution has stimulated the development of techniques to simulate BIOMASS acquisitions based on campaign data. The feasibility of tomographic imaging at BIOMASS resolution was first demonstrated in (Tebaldini and Rocca, 2012), where it was demonstrated that forest height in boreal forests could be retrieved to within an accuracy better than $4 \mathrm{~m}$ based on BIOMASS (simulated) data. The next relevant study on this subject is the one published in (Ho Tong Minh et al., 2015a), based on simulated BIOMASS acquisitions on tropical forests derived from the TropiSAR campaign, see figure 14 for a comparison between airborne and spaceborne tomography. In that paper, the correlation between in-situ AGB and tomographic intensity at $30 \mathrm{~m}$ was observed to be about 0.84 for plot sizes of about 6 ha when using BIOMASS data, whereas it was 0.97 using airborne data at full resolution (see section 5), hence providing evidence that use of tomography is expected to play a key role in the context of a spaceborne mission as well.
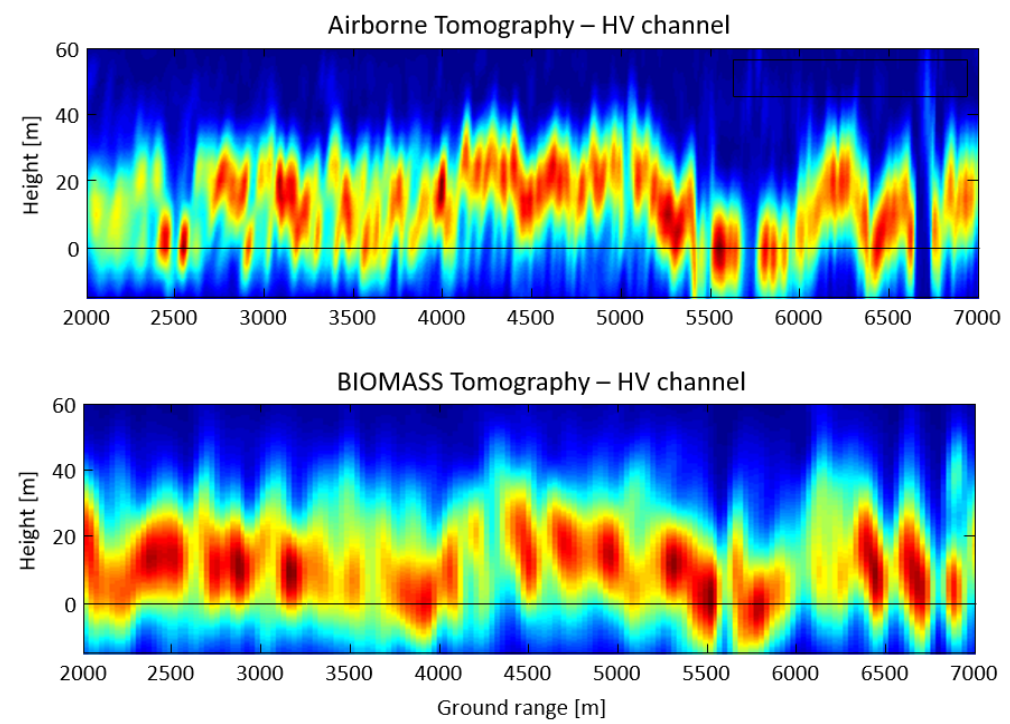

Figure 14: Airborne tomography (top panel) and BIOMASS tomography (bottom panel). Data: TropiSAR P-Band. Data acquisition by ONERA. Picture drawn from (Ho Tong Minh, 2014b).

The impact of temporal decorrelation was thoroughly studied in the frame of the long-term campaign TropiSCAT. The TropiSCAT campaign was implemented as a P-band fully polarimetric ground-based campaign, installed at the forest site of Paracou, French Guiana. The goal of the TropiSCAT campaign was to analyze the vertical distribution of temporal decorrelation in tropical forests. The system consists of 20 antennas installed on the 55-m high Guyaflux tower, each of which can be used as a transmitter or a receiver to form an equivalent monostatic vertical array of 15 elements for each polarization. The system was operated to collect tomographic data every 15 minutes for an overall period of about 1 year (Ho Tong Minh et al., 2013), (Ho Tong Minh et al., 2014b). Results published in (Ho Tong et al., 2014b) and (Ho Tong et al., 2015b) indicated that the degradation of tomographic imaging due to temporal decorrelation is acceptable as long as the time lag between two consecutive acquisitions is 4 days or less. A recent study considered the emulation of BIOMASS tomography by mixing acquisitions from TropiSCAT gathered every 3 days, including sunny and rainy days. Results showed a total radiometric error due to temporal decorrelation of 1-1.5 dB, which would entail a biomass retrieval error around about $20 \%$ or better at spatial scales on the order of 6 ha (Bai et al., 2018). 


\section{Conclusions}

SAR tomography is an increasingly studied technique to image the 3D structure of natural media, such as snow, ice, and vegetation. In the context of forest remote sensing, a most important finding is that tomographic intensity is significantly better correlated to forest AGB in tropical forests than conventional 2D SAR intensity, as it was observed in experimental data from two tropical sites in South America and three in equatorial Africa. Two possible reasons were considered to provide physical support to this finding, of both biophysical and electromagnetic nature: i) $30 \mathrm{~m}$ is a biophysically relevant height in dense tropical forests, and ii) ground scattering acts as a disturbing factor that needs to be removed. The following conclusions were drawn:

- The hypothesis that $30 \mathrm{~m}$ is a biophysically relevant height in dense tropical forests is strongly supported by ecological modelling (Chave, 1999) and by a reanalysis of Lidar data across Amazonia as published in (Meyer et al., 2018).

- Ground scattering (which includes terrain scattering and double scattering from trunk-ground and canopy-ground interactions) appears to be determined by a complex set of factors other than forest biomass, including local topography, tree density, understorey, and soil moisture. For this reason, it appears unlikely that ground scattering can be directly related to AGB in an operational context, at least in the absence of specific knowledge about local terrain and vegetation features.

In summary, tomography appears to bring the most complete information about AGB in tropical forests by virtue of its ability to single out the returns from different layers within the vegetation while rejecting ground scattering.

Besides forest biomass, SAR tomography was also demonstrated to be a powerful tool for mapping canopy height and subcanopy terrain topography, as shown by studies conducted at both boreal and tropical sites. Based on results from the recent literature, forest height can be retrieved by SAR tomography to within an accuracy better than $3 \mathrm{~m}$ in tropical forests, as validated through a pixel-to-pixel comparison against Lidar data. Retrieval of terrain topography under forests has been shown to be possible in both boreal forests and dense tropical forests, supporting the idea that SAR tomography might be used in a recent future as an alternative to Lidar mapping.

Tomography analyses of forested areas will be implemented for the first time from space during the tomographic phase of the BIOMASS mission. The tomographic phase of BIOMASS will last for the first 14 months of mission lifetime, providing global geographical coverage and enabling tomographic imaging with 7 passes acquired with a time lag of 3 days from one another. Notwithstanding many limitations w.r.t. airborne tomography, mostly arising from the coarser resolution and increased temporal decorrelation, studies based on simulated BIOMASS data derived from airborne campaign indicate that accurate tomographic imaging is feasible, and support the idea that forest AGB in tropical could be retrieved to within a $20 \%$ accuracy at spatial scales on the order of 6 ha.

\section{Acknowledgments}

All of the results presented within this paper were obtained in the frame of studies funded by the European Space Agency (ESA) in support of the BIOMASS mission, and we acknowledge ESA for the support it gave to the research on SAR Tomography over the last decade. This paper stemmed from the most fruitful Forest Properties Workshop organized in November 2017 in Bern (CH) by the International Space Science Institute (ISSI), which we wish to warmly acknowledge for this initiative. We also acknowledge various funding sources including CNES (France, TOSCA), and an "Investissement d'Avenir" program managed by Agence Nationale de la Recherche (CEBA, ref. ANR-10-LABX-25-01).

\section{References}

(AFRISAR, 2017), Technical Assistance for the Deployment of Airborne SAR and Geophysical Measurements during the AFRISAR Experiment, Final Report to ESA, 2017

(Aguilera et al., 2013) Aguilera E., Nannini M., Reigber A., "Wavelet-Based Compressed Sensing for SAR Tomography of Forested Areas," IEEE Transactions on Geoscience and Remote Sensing, vol. 51, no. 12, pp. 5283-5295, Dec. 2013 
(Bai et al., 2018) Y. Bai, S. Tebaldini, D. H. T. Minh and W. Yang, "An Empirical Study on the Impact of Changing Weather Conditions on Repeat-Pass SAR Tomography," in IEEE Journal of Selected Topics in Applied Earth Observations and Remote Sensing, doi: 10.1109/JSTARS.2018.2818796

(Banda et al., 2016) Banda, F., Dall, J., Tebaldini, S., Single and Multipolarimetric P-Band SAR Tomography of Subsurface Ice Structure, (2016) IEEE Transactions on Geoscience and Remote Sensing, 54 (5), art. no. 7366586, pp. 2832-2845, May. 2016

(BIOSAR, 2008), Technical Assistance for the Deployment of Airborne SAR and Geophysical Measurements during the BIOSAR 2007 Experiment, Final Report to ESA, 2008

(BIOSAR, 2009), Technical Assistance for the Deployment of Airborne SAR and Geophysical Measurements during the BIOSAR 2008 Experiment, Final Report to ESA, 2009

(Blomberg et al., 2018) E. Blomberg, L. Ferro-Famil, M. J. Soja, L. M. H. Ulander and S. Tebaldini, "Forest Biomass Retrieval From L-Band SAR Using Tomographic Ground Backscatter Removal," in IEEE Geoscience and Remote Sensing Letters, doi: 10.1109/LGRS.2018.2819884

(Budillon et al., 2011) A. Budillon, A. Evangelista and G. Schirinzi, "Three-Dimensional SAR Focusing From Multipass Signals Using Compressive Sampling," in IEEE Transactions on Geoscience and Remote Sensing, vol. 49, no. 1, pp. 488499, Jan. 2011.

(Chave, 1999) J.Chave, Study of structural, successional and spatial patterns in tropical rain forests using TROLL, a spatially explicit forest model," Ecological Modelling., vol. 124, nos. 2-3, pp. 233-254, Jun. 1999

(Curlander and McDonough, 1991) J.C. Curlander and R.N. McDonough, "Synthetic Aperture Radar", Wiley Interscience, New York, 1991

(ESA, 2012). Report for Mission Selection: Biomass, ESA SP-1324/1 (3 volume series), European Space Agency, Noordwijk, The Netherlands, 2012

(ESA, 2015) ESA, SAOCOM-CS Mission Science Document, ESA, EOP-SM/2764/, 2015

(Freeman, 2007) A. Freeman, "Fitting a two-component scattering model to polarimetric SAR data from forests," Geoscience and Remote Sensing, IEEE Transactions on, vol. 45, no. 8, pp. 2583-2592, Aug. 2007

(Freeman and Durden, 1998) A. Freeman and S. L. Durden, "A three-component scattering model for polarimetric SAR data," in IEEE Transactions on Geoscience and Remote Sensing, vol. 36, no. 3, pp. 963-973, May 1998.

(Frey and Meier, 2011a) O. Frey and E. Meier, "Analyzing Tomographic SAR Data of a Forest With Respect to Frequency, Polarization, and Focusing Technique," in IEEE Transactions on Geoscience and Remote Sensing, vol. 49, no. 10, pp. 36483659 , Oct 2011.

(Frey and Meier, 2011b)O. Frey and E. Meier, "3-D Time-Domain SAR Imaging of a Forest Using Airborne Multibaseline Data at L- and P-Bands," in IEEE Transactions on Geoscience and Remote Sensing, vol. 49, no. 10, pp. 3660-3664, Oct. 2011.

(Frei et al., 2009) O. Frey, C. Magnard, M. Ruegg and E. Meier, "Focusing of Airborne Synthetic Aperture Radar Data From Highly Nonlinear Flight Tracks," in IEEE Transactions on Geoscience and Remote Sensing, vol. 47, no. 6, pp. 18441858, June 2009.

(Frey et al., 2016) O. Frey, C. L. Werner, R. Caduff and A. Wiesmann, "A time series of SAR tomographic profiles of a snowpack," Proceedings of EUSAR 2016: 11th European Conference on Synthetic Aperture Radar, Hamburg, Germany, 2016, pp. 1-5.

(Gini et al., 2002) Gini F., Lombardini F., Montanari M., Layover solution in multibaseline SAR interferometry, Aerospace and Electronic Systems, IEEE Transactions on, vol. 38, no. 4, pp. 1344,1356, Oct 2002

(Ho Tong Minh et al., 2013) Ho Tong Minh, D., Tebaldini, S., Rocca, F., Koleck, T., Borderies, P., Albinet, C., Villard, L., Hamadi, A., Le Toan, T., Ground-based array for tomographic imaging of the tropical forest in p-band, (2013) IEEE Transactions on Geoscience and Remote Sensing, 51 (8), art. no. 6488812, pp. 4460-4472, Aug. 2013

(Ho Tong Minh et al., 2014a) Ho Tong Minh, D., Le Toan, T., Rocca, F., Tebaldini, S., D'Alessandro, M.M., Villard, L., Relating P-band synthetic aperture radar tomography to tropical forest biomass, (2014) IEEE Transactions on Geoscience and Remote Sensing, 52 (2), art. no. 6488809, pp. 967-979, Feb. 2014 
(Ho Tong Minh et al., 2014b) Ho Tong Minh, D., Tebaldini, S., Rocca, F., Le Toan, T., Borderies, P., Koleck, T., Albinet, C., Hamadi, A., Villard, L., Vertical structure of p-band temporal Decorrelation at the Paracou forest: Results from Tropiscat, (2014) IEEE Geoscience and Remote Sensing Letters, 11 (8), art. no. 6708421, pp. 1438-1442, Aug. 2014

(Ho Tong Minh et al., 2015a) D. Ho Tong Minh, S. Tebaldini, F. Rocca, T. Le Toan, L. Villard and P. C. DuboisFernandez, "Capabilities of BIOMASS Tomography for Investigating Tropical Forests," in IEEE Transactions on Geoscience and Remote Sensing, vol. 53, no. 2, pp. 965-975, Feb. 2015.

(Ho Tong Minh et al., 2015b) Ho Tong Minh, D., Tebaldini, S., Rocca, F., Le Toan, T., The Impact of Temporal Decorrelation on BIOMASS Tomography of Tropical Forests, (2015) IEEE Geoscience and Remote Sensing Letters, 12 (6), art. no. 7042801, pp. 1297-1301, June 2015

(Ho Tong Minh et al., 2016) Ho Tong Minh, D., Le Toan, T., Rocca, F., Tebaldini, S., Villard, L., Réjou-Méchain, M., Phillips, O.L., Feldpausch, T.R., Dubois-Fernandez, P., Scipal, K., Chave, J., SAR tomography for the retrieval of forest biomass and height: Cross-validation at two tropical forest sites in French Guiana, (2016) Remote Sensing of Environment, 175, pp. 138-147, March 2016

(Huang et al., 2017) Y. Huang, J. Levy-Vehel, L. Ferro-Famil and A. Reigber, "Three-Dimensional Imaging of Objects Concealed Below a Forest Canopy Using SAR Tomography at L-Band and Wavelet-Based Sparse Estimation," in IEEE Geoscience and Remote Sensing Letters, vol. 14, no. 9, pp. 1454-1458, Sept. 2017.

(Labrière et al., 2018) Labrière, N.; Tao, S.; Chave, jerôme; Scipal, K.; Le Toan, T.; Abernethy, K.; Alonso, A.; Barbier, N.; Bissiengou, P.; Casal, T.; Davies, S. J.; Ferraz, A.; Hérault, B.; Jaouen, G.; Jeffery, K. J.; Kenfack, D.; Korte, L.; Lewis, S. L.; Malhi, Y.; Memiaghe, H. R.; Poulsen, J. R.; Réjou-Méchain, M.; Villard, L.; Vincent, G.; White, L. J. T.; Saatchi, S. In situ reference datasets from the TropiSAR and AfriSAR campaigns in support of upcoming spaceborne biomass missions. JSTARS 2018 (in press).

(Lavalle et al., 2017) M. Lavalle, B. Hawkins, and S. Hensley, “Tomographic Imaging with UAVSAR: Current status and new results from the 2016 AfriSAR campaign, " in 2017 IEEE International Geoscience and Remote Sensing Symposium (IGARSS), July 2017

(Lin and Sarabandi, 1992) Y.-C. Lin and K. Sarabandi, "Electromagnetic scattering model for a tree trunk above a tilted ground plane," Geoscience and Remote Sensing, IEEE Transactions on, vol. 33, no. 4, pp. 1063-1070, Jul 1995.

(Mancon et al., 2017) Mancon, S., Monti Guarnieri, A., Giudici, D., Tebaldini, S., On the Phase Calibration by Multisquint Analysis in TOPSAR and Stripmap Interferometry, (2017) IEEE Transactions on Geoscience and Remote Sensing, 55 (1), art. no. 7589090, pp. 134-147, Jan. 2017

(Maréchaux and Chave, 2017) Maréchaux, I. and Chave, J. (2017), An individual-based forest model to jointly simulate carbon and tree diversity in Amazonia: description and applications. Ecol Monogr, 87: 632-664. doi:10.1002/ecm.1271

(Mariotti d'Alessandro and Tebaldini., 2012) M. Mariotti d'Alessandro and S. Tebaldini, "Phenomenology of P-Band Scattering From a Tropical Forest Through Three-Dimensional SAR Tomography," in IEEE Geoscience and Remote Sensing Letters, vol. 9, no. 3, pp. 442-446, May 2012.

(Mariotti d'Alessandro et al., 2013) Mariotti D'Alessandro, M., Tebaldini, S., Rocca, F., Phenomenology of ground scattering in a tropical forest through polarimetric synthetic aperture radar tomography, (2013) IEEE Transactions on Geoscience and Remote Sensing, 51 (8), art. no. 6484135, pp. 4430-4437, Aug. 2013

(Mariotti d'Alessandro and Tebaldini, 2018) M. Mariotti d'Alessandro and S. Tebaldini, Retrieval of Terrain Topography in Tropical Forests using P-Band SAR Tomography, IGARSS 2018, Valencia, 2018

(Meyer et al., 2018) V. Meyer et al. . et al., 'Canopy Area of Large Trees Explains Aboveground Biomass Variations across Nine Neotropical Forest Landscapes', Biogeosciences Discuss., 2018, 10.5194/bg-2017-547, available at https://www.biogeosciences-discuss.net/bg-2017-547/bg-2017-547.pdf

(Molino and Sabatier, 2001) Molino, J. F., and D. Sabatier. 2001. Tree diversity in tropical rain forests: A validation of the intermediate disturbance hypothesis. Science 294: 17021704.

(Moreira, 2014) A. Moreira, "A golden age for spaceborne SAR systems," 2014 20th International Conference on Microwaves, Radar and Wireless Communications (MIKON), Gdansk, 2014, pp. 1-4, doi: 10.1109/MIKON.2014.6899903

(Moreira et al, 2015) A. Moreira et al., "Tandem-L: A Highly Innovative Bistatic SAR Mission for Global Observation of Dynamic Processes on the Earth's Surface," in IEEE Geoscience and Remote Sensing Magazine, vol. 3, no. 2, pp. 8-23, June 2015. 
(Paillou et al., 2003) Paillou P., Grandjean G., Baghdadi N., Heggy E., August-Bernex Th., Achache J., "Sub-surface imaging in central-southern Egypt using low frequency radar: Bir Safsaf revisited," in IEEE Trans. Geosci. Remote Sensing, vol. 41, no. 7, pp. 1672-1684, 2003

(Pardini et al., 2014) M. Pardini, A. Cantini, F. Lombardini and K. Papathanassiou, "3-D Structure Of Forests: First Analysis of Tomogram Changes Due to Weather and Seasonal Effects at L-Band," EUSAR 2014; 10th European Conference on Synthetic Aperture Radar, Berlin, Germany, 2014, pp. 1-4.

(Pardini et al., 2017) M. Pardini and K. Papathanassiou, "On the Estimation of Ground and Volume Polarimetric Covariances in Forest Scenarios With SAR Tomography," in IEEE Geoscience and Remote Sensing Letters, vol. 14, no. 10, pp. 1860-1864, Oct. 2017.

(Papathanassiou and Cloude, 2001) Papathanassiou K.P., Cloude S.R., Single baseline polarimetric SAR interferometry, IEEE Transaction on Geosciences and Remote Sensing, vol. 39, no. 11, November 2001

(Ponce et al., 2014) Ponce O., Prats-Iraola P., Scheiber R., Reigber A., Moreira A., Aguilera E., Polarimetric 3-D Reconstruction From Multicircular SAR at P-Band, IEEEGeoscience and Remote Sensing Letters, vol. 11, no. 4, pp. 803,807, April 2014

(Reigber and Moreira, 2000) Reigber A., Moreira A., First demonstration of airborne SAR tomography using multibaseline L-band data, IEEE Transactions on Geoscience and Remote SensingRemote Sensing, vol. 38, no. 5, pp. 2142,2152, Sep 2000

(Rekioua et al., 2017) Rekioua, B., Davy, M., Ferro-Famil, L., Tebaldini, S., Snowpack permittivity profile retrieval from tomographic SAR data, (2017) Comptes Rendus Physique, Volume 18, Issue 1, Pages 57-65, Jan. 2017

(Sarabandi, 1992) K. Sarabandi, "Scattering from dielectric structures above impedance surfaces and resistive sheets," Antennas and Propagation, IEEE Transactions on, vol. 40, no. 1, pp. 67-78, Jan 1992.

(Smith-Jonforsen et al., 2005) G. Smith-Jonforsen, L. Ulander, and X. Luo, "Low vhf-band backscatter from coniferous forests on sloping terrain," Geoscience and Remote Sensing, IEEE Transactions on, vol. 43, no. 10, pp. 2246-2260, Oct. 2005.

(Tebaldini, 2009) Tebaldini, S., Algebraic synthesis of forest scenarios from multibaseline PolInSAR data,(2009) IEEE Transactions on Geoscience and Remote Sensing, 47 (12), art. no. 5226569, pp. 4132-4142, Dec. 2009

(Tebaldini and Monti Guarnieri., 2010) Tebaldini, S., Monti Guarnieri, A., On the role of phase stability in SAR multibaseline applications,(2010) IEEE Transactions on Geoscience and Remote Sensing, 48 (7), art. no. 5443544, pp. 2953-2966, July 2010

(Tebaldini and Rocca, 2012) Tebaldini, S., Rocca, F., Multibaseline polarimetric SAR tomography of a boreal forest at Pand L-Bands, (2012) IEEE Transactions on Geoscience and Remote Sensing, 50 (1), art. no. 5961624, pp. 232-246, Jan. 2012

(Tebaldini et al., 2016a) Tebaldini, S., Rocca, F., Mariotti D'Alessandro, M., Ferro-Famil, L., Phase calibration of airborne tomographic SAR data via phase center double localization, (2016) IEEE Transactions on Geoscience and Remote Sensing, 54 (3), art. no. 7308057, pp. 1775-1792, March 2016

(Tebaldini et al., 2016b) Tebaldini, S., Nagler, T., Rott, H., Heilig, A., Imaging the Internal Structure of an Alpine Glacier via L-Band Airborne SAR Tomography, (2016) IEEE Transactions on Geoscience and Remote Sensing, 54 (12), pp. 7197 7209, Dec. 2016

(Torano Caicoya et al., 2015) A. Toraño Caicoya, M. Pardini, I. Hajnsek and K. Papathanassiou, "Forest Above-Ground Biomass Estimation From Vertical Reflectivity Profiles at L-Band," in IEEE Geoscience and Remote Sensing Letters, vol. 12, no. 12 , pp. 2379-2383, Dec. 2015

(Treuhaft and Siquiera, 2000) Treuhaft, R. N., and P. R. Siqueira, Vertical structure of vegetated land surfaces from interferometric and polarimetric radar, Radio Sci., 35(1), 141-177, 2000, doi: 10.1029/1999RS900108.

(TROPISAR, 2011), Technical Assistance for the Deployment of Airborne SAR and Geophysical Measurements during the TROPISAR 2009 Experiment, Final Report to ESA, 2011

(Truong-Loi et al., 2015) M. L. Truong-Loï, S. Saatchi and S. Jaruwatanadilok, "Soil Moisture Estimation Under Tropical Forests Using UHF Radar Polarimetry," in IEEE Transactions on Geoscience and Remote Sensing, vol. 53, no. 4, pp. 17181727, April 2015. 
(Ulaby et al., 1998) F. Ulaby, K. McDonald, K. Sarabandi, and M. Dobson, "Michigan microwave canopy scattering models (mimics)," Geoscience and Remote Sensing Symposium, 1988. IGARSS '88. Remote Sensing: Moving Toward the 21st Century., International, vol. 2, pp. 1009-1009, Sep 1988.

(Yitayew et al., 2017) Yitayew, T.G., Ferro-Famil, L., Eltoft, T., Tebaldini, S., Lake and Fjord Ice Imaging Using a Multifrequency Ground-Based Tomographic SAR System, (2017) IEEE Journal of Selected Topics in Applied Earth Observations and Remote Sensing, 10 (10), art. no. 7983458, pp. 4457-4468, Oct. 2017

(Zhu and Bamler, 2012), X. X. Zhu and R. Bamler, "Super-Resolution Power and Robustness of Compressive Sensing for Spectral Estimation With Application to Spaceborne Tomographic SAR," in IEEE Transactions on Geoscience and Remote Sensing, vol. 50, no. 1, pp. 247-258, Jan. 2012. 